\title{
BMJ Open Quality Evaluation of a learning collaborative to advance team-based care in Federally Qualified Health Centers
}

To cite: Thies K, Schiessl A, Khalid N, et al. Evaluation of a learning collaborative to advance team-based care in Federally Qualified Health Centers. BMJ Open Quality 2020;9:e000794. doi:10.1136/ bmjoq-2019-000794

Received 18 August 2019 Revised 28 April 2020 Accepted 26 May 2020

\section{Check for updates}

(c) Author(s) (or their employer(s)) 2020. Re-use permitted under CC BY-NC. No commercial re-use. See rights and permissions. Published by BMJ.

Weitzman Institute, Community Health Center Inc, Middletown, Connecticut, USA

Correspondence to

Dr Kathleen Thies;

thiesk@chc1.com

Kathleen Thies (D), Amanda Schiessl, Nashwa Khalid, Anne Marie Hess, Kasey Harding, Deborah Ward

\section{ABSTRACT}

Practising team-based primary care allows Federally Qualified Health Centers (FQHC) in the USA to be accredited as patient-centred medical homes, positioning them for value-based models of shared savings in healthcare costs. Team-based care (TBC) involves redesign of staff roles and care delivery processes to improve efficiency and effectiveness, which requires a systematic and supportive approach to practice change over time. Thirteen FQHC primary care teams participated in an 8-month learning collaborative with a goal of providing teams with the knowledge, skills and coaching support needed to advance TBC in their organisations. The primary aim was to evaluate self-reported changes in FQHC teams assessment of their practice relative to key concepts of TBC. The secondary aim was to evaluate how teams used the collaborative to develop new skills to advance TBC, and the implementation, service and patient outcomes they achieved. Site visits were conducted with three teams 6 months postcollaborative. Results: Two teams withdrew. The remaining teams embarked on 15 TBC improvement initiatives. Nine teams submitted a total of 11 playbooks to guide other staff in changes to their practice. Three teams reported improved efficiencies at the service level (screening and scheduling), and one improved outcomes in patients with diabetes. The nine teams that completed precollaborative and postcollaborative self-assessments reported improvements in their practice and in coach and team skills. Site visits revealed that actionable data were a barrier to improvement, coaching support from the collaborative was highly valued and FQHC leadership support was critical to improvement. Leadership investment in developing their primary care teams' quality improvement, coaching and data analytical skills can advance TBC in their organisations.

\section{INTRODUCTION}

Team-based care (TBC) is one of the 10 building blocks of high-performing primary care, and has been shown to result in better health outcomes, higher patient satisfaction, decreased provider burnout and improved patient access. ${ }^{1-5}$ It clarifies roles and responsibilities of clinicians and staff, reduces duplication of tasks and poor communication, and standardises day-to-day processes such as scheduling and screening. Care teams provide patients with greater continuity of care and management of chronic conditions, such as diabetes. ${ }^{1-5}$ TBC is a component of the patient-centred medical homes $(\mathrm{PCMH})$ programme in the USA. ${ }^{12}{ }^{4}$ For Federally Qualified Health Centers (FQHC), which care for 29 million poor and underserved patients in the USA, accreditation as a PCMH positions them for the shift from fee for service to value-based 'mixed models' of shared savings, and case-based care. ${ }^{6-9}$

\section{Problem}

For FQHCs, advancing TBC requires restructuring and redesign of staff roles and responsibilities, as well as workflows, in order to improve efficiency and clinical effectiveness. ${ }^{10-13}$ Such a transition requires a systematic and supportive approach over time, as it is often difficult to change long-established patterns of practice. The approach described in this paper was a learning collaborative for TBC in FQHCs.

\section{Available knowledge and rationale}

The learning collaborative was adapted from the Institute for Healthcare Improvement's Breakthrough Series, which are designed to kick-start organisations' improvement efforts. ${ }^{1415}$ Consistent with that model, our collaborative included knowledge about the central concepts of TBC, practice selfassessment tools relative to TBC for participants to identify areas for improvement, and development of quality improvement (QI) and data analytical skills to make those improvements. ${ }^{16-20}$ We also provided a structured coaching programme ${ }^{21}$ to guide the primary care teams in their redesign work. This type of coaching, also called facilitation, has been demonstrated to be key to the success of organisations' efforts to improve practice. $^{22} 23$

\section{Aim}

Our goal was to provide primary care teams with the knowledge, skills and support needed 
Table 1 The 13 FQHCs that participated in the learning collaborative

\begin{tabular}{llcll}
\hline $\begin{array}{l}\text { Participating } \\
\text { organisation }\end{array}$ & State & $\begin{array}{c}\text { Practice } \\
\text { sites (n) }\end{array}$ & $\begin{array}{l}\text { Number of patients } \\
\text { (2018 UDS data) }\end{array}$ & Role of coach in the organisation \\
\hline Site 1 & VA & 19 & 43303 & Registered nurse risk management coordinator \\
\hline Site 2 & TX & 4 & 15445 & Family nurse practitioner \\
\hline Site 3 & MA & 8 & 26635 & Registered nurse quality improvement coordinator \\
Site 4 & CA & 15 & 2300 & Clinic operations manager \\
Site 5 & PA & 5 & 21833 & Patient services centre manager \\
Site 6 & MD & 2 & 6582 & Registered nurse \\
Site 7 & VA & 3 & 9360 & Paediatric nurse practitioner and medical director \\
\hline Site 8 & MI & 5 & 6519 & Director of programmes \\
Site 9 & NJ & 9 & 28735 & Regional practice director \\
\hline Site 10 & CT & 23 & 49527 & Practice coach \\
Site 11 & MI & 22 & 15017 & Operations director \\
Site 12 & WA & 3 & 29568 & Quality and accreditation coordinator \\
\hline Site 13 & CA & 20 & 57930 & Physician assistant \\
\hline
\end{tabular}

FQHC, Federally Qualified Health Center; UDS, Uniform Data Set.

to advance $\mathrm{TBC}$ in their organisations, a process that would continue beyond the collaborative. The primary aim was to evaluate self-reported changes in FQHC teams' assessment of their practice as a result of learning about and applying the central concepts of TBC. The secondary aim was to evaluate how teams used the collaborative to develop new skills to advance TBC, and the implementation, service and patient outcomes they achieved by the end of the collaborative.

\section{METHODS}

\section{Context: setting and participants}

The TBC learning collaborative was supported by a National Cooperative Agreement (NCA) grant from the US Department of Health and Human Services Health Resources and Services Administration (HRSA) to Community Health Center, Inc (CHCI) and its Weitzman Institute (WI), the research and education division of CHCI. CHCI is a multisite FQHC and level III PCMH in Connecticut providing comprehensive care to over 100000 medically underserved patients annually.

The opportunity to apply for learning collaborative participation was publicised in the Primary Care Digest, a weekly HRSA publication. Structured interviews were held with 20 applicant FQHCs. Table 1 describes the 13 FQHCs selected based on alignment of TBC with organisational goals, commitment that their teams would have the time and data to participate in the collaborative, and confirmation that teams could make decisions about practice change at the team level. Previous experience with QI skills was preferred but not required. Leadership in selected organisations acknowledged these expectations in writing.

The 13 FQHCs committed a core and extended primary care team from a practice site within their health centre to participate in the collaborative. The core team consisted of the three to seven individuals who work together every day to care for a panel of patients, such as primary care providers, behavioural health specialist, nurses, medical assistants and non-clinical staff. The extended team consisted of clinicians and staff who work with multiple teams, such as a pharmacist or nutritionist. Each FQHC also designated a team member as the improvement coach to guide the team through the work of the collaborative, and to participate in the structured coaching programme. Coaches were not required to have previous experience.

\section{Patient and public involvement}

Patients were not involved in the development of the learning collaborative or its evaluation.

\section{Description of the intervention}

Table 2 describes the structure and content of the learning collaborative, which was implemented by the NCA team at CHCI/WI. We began with a 2-day in-person training for team coaches, followed by an 8-month programme of seven videoconference interactive learning sessions, weekly meetings of the FQHC teams at their sites and weekly sessions between FQHC improvement coaches and their NCA mentor-coaches (coach-mentor calls). Self-assessment tools allowed teams to measure their practice against best practices in TBC.

The central concepts of TBC included the building blocks of primary care ${ }^{411}$ : clarifying roles and responsibilities of core and extended team members to capitalise on their training; team huddles to improve communication; tracking cycle time for efficient office visits; previsit planning to improve compliance with scheduled tests and screenings; and population health. 
Table 2 Structure and content of learning collaborative on team-based care

\begin{tabular}{l}
\hline Intervention \\
Two-day in-person coaching and quality \\
improvement (QI) boot camp
\end{tabular}

Seven live interactive videoconference learning sessions, 90 min each

Self-assessment tools

Weekly live videoconference coachmentor calls, 60 min each

Team assignments curricular syllabus

\section{Description}

FQHC coach and at least one other team member attended the boot camp, which focused on the art of coaching, and using QI and data analytical skills to systematically undertake improvement initiatives towards the goal of advancing team-based care.

Learning sessions included: didactics on the central concepts and practices of TBC; FQHC progress reports; refreshers in QI methods; and discussion. Learning sessions were video recorded and posted to an online learning community.

FQHC teams are assigned the following tools to complete, and to discuss the results with their teams during initial meetings:

- Primary care team guide assessment ${ }^{29}$

- Coach skills self-assessment ${ }^{30}$

- Team skills self-assessment ${ }^{31}$

Teams were expected to meet weekly for an hour working their way up the improvement ramp as a guide to changing their practice, and to upload seven completed QI tools onto an online learning community by the end of the collaborative.

Content posted included: a syllabus with links to self-assessment tools; QI materials and resources on team-based care; a discussion board; and folders for each team to upload assignments accessible by all teams.

Two experienced $\mathrm{CHCl} \mathrm{QI}$ coaches (NCA coach-mentors) held weekly videoconference calls with a group of FQHC team coaches to assess team progress, provide feedback and support regarding assignments, QI tools and managing team dynamics. Extensive notes were taken during these weekly calls.

CHCl, Community Health Center, Inc; FQHC, Federally Qualified Health Center; NCA, National Cooperative Agreement; TBC, teambased care.

The QI skills focused on using the improvement ramp, a data-based systematic approach to changing practice. $^{24}{ }^{25}$ First, teams assessed their practice, and then used fishbones and process maps to focus on a specific improvement initiative, such as improving the efficiency of routine screening. They developed global and measurable specific aim statements for the initiative, followed by conducting Plan-Do-Study-Act cycles to trial new workflows and responsibilities. At the top of the ramp, teams developed a step-by-step guide, called a playbook, for staff to spread the improvement across their health centre.

\section{Description of the intervention: execution of the learning collaborative by the NCA team}

The NCA team met weekly to focus on lead measures related to team progress ${ }^{26-28}$ : team participation in learning sessions and weekly coach-mentor calls; issues discussed during those calls; number and quality of completed assignments; and FQHC coach contact with the NCA team for further support. All NCA team members listened to the weekly coach-mentor calls.

\section{Study of the intervention: measures and analysis}

The primary aim to evaluate self-reported changes in FQHC teams' assessment of their practice used the measures listed below before and after participation.

- Primary care team guide assessment ${ }^{29}$ has 24 items representing $\mathrm{TBC}$ activities in 15 domains. Items are rated 1-12 across four levels of performance, with higher scores indicating higher performance: A (rating of 10-12); B (rating of 7-9); C (rating of 4-6); and $\mathrm{D}$ (rating of $1-3$ ). Total scores could range from 24 to 288.

- Coach skills self-assessment ${ }^{30}$ has 38 items in five skill domains. Each item is rated 0-10 across four levels of performance, with higher scores indicating higher performance: (0) want to learn; (1-2) novice; (3-4) advanced beginner; (5-6) competent; (7-8) proficient; (9-10) expert. Total scores could range from 0 to 380 .

- The team skills self-assessment ${ }^{31}$ has 21 items in five skill domains. Each item is rated as follows: (1) strongly disagree; (2) disagree; (3) agree; (4) strongly agree. Total scores could range from 21 to 84, with higher scores indicating higher level of performance. The secondary aim to evaluate how teams used the collaborative to develop new skills and advance TBC was measured using Proctor's ${ }^{32}$ implementation, practice and patient outcomes. First, we measured the implementation outcome acceptability, defined as participant satisfaction with the collaborative, using surveys after the 2-day coaching and boot camp and each learning session.

Second, we measured the implementation outcome adoption/uptake, defined as actions by the individual teams to use the activities and resources of the collaborative: per cent attendance at learning sessions and at coach-mentor calls; consistency of hosting team weekly meetings; and number of QI assignments completed for teams' improvement initiatives. Third, service outcomes and patient outcomes were self-reports by teams related to these initiatives, such as improved efficiency in screening and improvement in measures of patient health status respectively. 


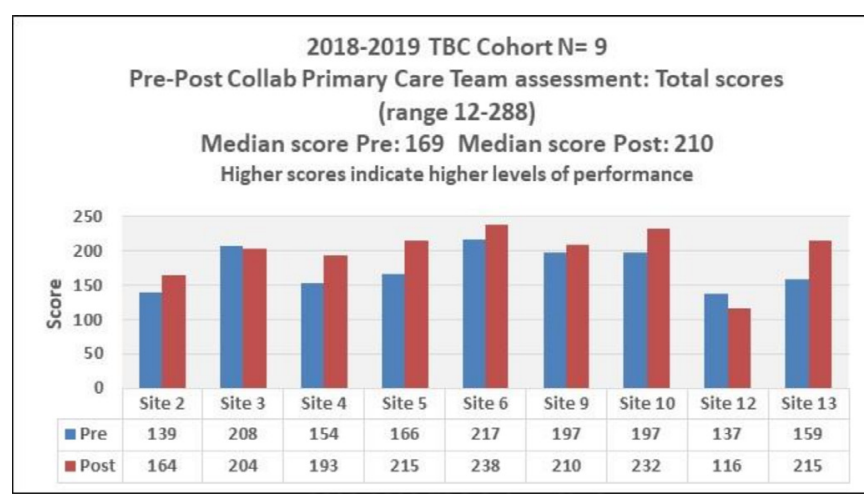

Figure 1 Prescore and postscore on the primary care team assessment. TBC, team-based care.

Site visits were conducted with three teams 6 months after the collaborative. Structured interviews addressed facilitators and barriers related to advancing TBC: coach and team functioning; use of QI and data skills; spread and sustainability of TBC model; and organisational leadership and support.

\section{RESULTS}

Primary aim

The primary care team guide assessment ${ }^{29}$ was completed by all 13 teams precollaborative and nine teams postcollaborative. For these nine teams, a one-tailed t-test assuming unequal variance did not support significant improvements in total scores $(\mathrm{p}=0.057)$ overall, despite an average increase of 24 points across the teams. Figure 1 shows precomparison and postcomparison of the teams' scores. Table 3 lists the precollaborative and postcollaborative levels of performance in 15 domains for the nine teams. There were shifts in five domains to higher levels of performance: practice team overall, registered nurse, laypersons, population management and medication management. While no teams reported a level A (highest level) on the practice team domain precollaborative, four did so postcollaborative.

Most teams also reported decreased levels of performance postcollaborative in some domains, which might be attributed to social desirability bias. ${ }^{33}$ That is, teams' self-assessment of their practice prior to the learning collaborative may have been overly favourable, and that as they learnt more about $\mathrm{TBC}$, they applied a more rigorous interpretation of TBC to their practice.

The coach skills self-assessment ${ }^{30}$ tool was completed precollaborative and postcollaborative by eight respondents from seven FQHC sites; site 5 had two coaches. A two-tailed paired $\mathrm{t}$-test ${ }^{34}$ by respondent supported a significant increase in total scores precollaborative to postcollaborative $(\mathrm{p}=0.0032,95 \% \mathrm{CI}-157.04$ to -46.95$)$ (figure 2). After collaborative, the eight respondents rated themselves higher in all five domains increasing their total scores.

The team skills self-assessment ${ }^{31}$ was completed by 25 respondents both precollaborative and postcollaborative,

Table 3 Prechange and postchange in levels on the primary care team guide assessment

Primary care team guide assessment: $n=9$ sites

Changes in level before/after in 15 domains by site and by domain

\begin{tabular}{|c|c|c|c|c|c|c|c|c|c|}
\hline \multirow[b]{2}{*}{ Domain } & \multicolumn{9}{|c|}{ Sites } \\
\hline & Site 2 & Site 3 & Site 4 & Site 5 & Site 6 & Site 9 & Site 10 & Site 12 & Site 13 \\
\hline The practice team & $\mathrm{B}$ & B & B & $\uparrow \mathrm{B} / \mathrm{A}$ & $\uparrow \mathrm{B} / \mathrm{A}$ & $\uparrow \mathrm{B} / \mathrm{A}$ & $\uparrow \mathrm{B} / \mathrm{A}$ & $\mathrm{C}$ & B \\
\hline Registered nurse (RN) & $\uparrow \mathrm{D} / \mathrm{C}$ & $\downarrow A / B$ & $\uparrow \mathrm{B} / \mathrm{A}$ & D & $\uparrow \mathrm{B} / \mathrm{A}$ & $\uparrow \mathrm{D} / \mathrm{C}$ & $\uparrow \mathrm{C} / \mathrm{B}$ & C & $\uparrow \mathrm{D} / \mathrm{C}$ \\
\hline Laypersons & $\uparrow \mathrm{C} / \mathrm{B}$ & $\downarrow \mathrm{A} / \mathrm{B}$ & $\uparrow \mathrm{D} / \mathrm{A}$ & B & B & $\uparrow \mathrm{C} / \mathrm{B}$ & A & $\uparrow \mathrm{C} / \mathrm{B}$ & $\uparrow \mathrm{D} / \mathrm{B}$ \\
\hline Enhancing access & $\downarrow \mathrm{A} / \mathrm{B}$ & $\mathrm{B}$ & $A$ & $\uparrow \mathrm{B} / \mathrm{A}$ & $\mathrm{B}$ & $\uparrow \mathrm{B} / \mathrm{A}$ & B & $\downarrow \mathrm{B} / \mathrm{C}$ & $A$ \\
\hline Self-management support & $\downarrow \mathrm{B} / \mathrm{C}$ & B & $\mathrm{D}$ & $\uparrow \mathrm{C} / \mathrm{B}$ & B & B & A & $\mathrm{D}$ & B \\
\hline Population management & $\downarrow \mathrm{B} / \mathrm{C}$ & A & $\uparrow \mathrm{B} / \mathrm{A}$ & C & $\uparrow \mathrm{B} / \mathrm{A}$ & $\downarrow \mathrm{A} / \mathrm{B}$ & $\uparrow \mathrm{C} / \mathrm{B}$ & $\downarrow C / D$ & $\uparrow \mathrm{D} / \mathrm{C}$ \\
\hline Planned care & $\downarrow \mathrm{B} / \mathrm{C}$ & A & $\downarrow \mathrm{B} / \mathrm{C}$ & $\uparrow B / A$ & $\uparrow \mathrm{B} / \mathrm{A}$ & $\downarrow \mathrm{A} / \mathrm{B}$ & B & $\downarrow \mathrm{C} / \mathrm{D}$ & $\uparrow \mathrm{C} / \mathrm{B}$ \\
\hline Care management & $\downarrow \mathrm{B} / \mathrm{C}$ & $\mathrm{B}$ & $\uparrow \mathrm{C} / \mathrm{B}$ & $\uparrow \mathrm{B} / \mathrm{A}$ & $A$ & $A$ & $\uparrow \mathrm{B} / \mathrm{A}$ & $\mathrm{C}$ & $\uparrow \mathrm{C} / \mathrm{A}$ \\
\hline $\begin{array}{l}\text { Communication } \\
\text { management }\end{array}$ & B & $\mathrm{B}$ & $\mathrm{B}$ & $\uparrow \mathrm{B} / \mathrm{A}$ & B & $\downarrow \mathrm{A} / \mathrm{B}$ & A & $\uparrow \mathrm{C} / \mathrm{B}$ & $\uparrow \mathrm{C} / \mathrm{A}$ \\
\hline $\begin{array}{l}\text { Clinic-community } \\
\text { connections }\end{array}$ & C & $\downarrow \mathrm{A} / \mathrm{B}$ & $\uparrow \mathrm{C} / \mathrm{B}$ & B & A & B & $A$ & $\uparrow \mathrm{C} / \mathrm{B}$ & A \\
\hline
\end{tabular}

$\uparrow$ Indicates increase in self-reported performance Pre/Post. $\downarrow$ Indicates decrease self-reported performance Pre/Post. Single letter indicates no change Pre/Post. 


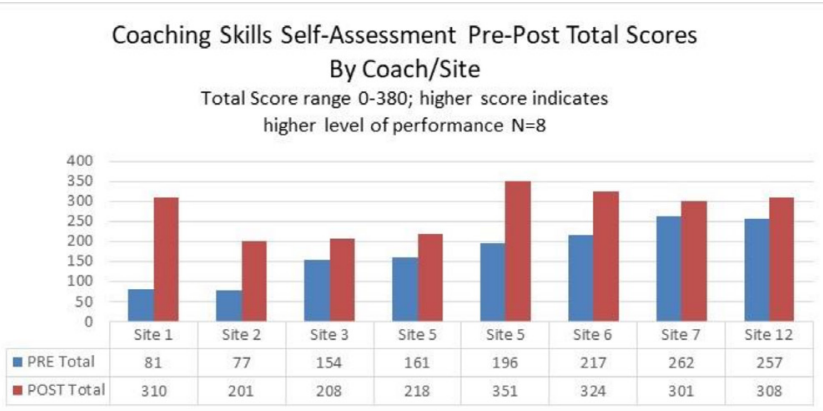

Figure 2 Prescore and postscore on the coaching skills self-assessment.

representing eight FQHC sites. A paired t-test ${ }^{34}$ by respondent supported a significant increase in total scores precollaborative to postcollaborative $(\mathrm{p}<0.000,95 \% \mathrm{CI}$ -12.4 to -5.9$)$. When the data were examined by domain rather than respondent, significant increases were found in all five domains of team skills: data skills; effective meetings; implementing daily huddles; improvement skills; and teamwork.

\section{Secondary aim}

Satisfaction with the 2-day in-person coaching and QI boot camp was high, with $91 \%-100 \%$ agreeing/strongly agreeing on all 11 items that it was helpful. Satisfaction with the seven learning sessions was also high, ranging from $92 \%$ to $100 \%$ for agree/strongly agree on 11 of the 12 items. The 12th question was worded in a way that made responses difficult to interpret.

The secondary aim was to evaluate how teams used the collaborative to develop new skills, and the implementation, service and patient outcomes they achieved by the end of the collaborative. Table 4 summarises implementation, service and patient outcomes at the team level for the 13 FQHC teams selected for the collaborative. Teams met with varying consistency and two teams ultimately withdrew due to competing priorities. The teams embarked on 15 improvement initiatives, 11 of which resulted in playbooks. Eight teams submitted all seven QI assignments for their initiatives. Three teams reported data supporting improved efficiency in service outcomes: routine screening (2), and rescheduling patients who did not show up for appointments (1). One team reported data supporting improved outcomes among patients with uncontrolled diabetes.

\section{Site visits}

Structured interviews during visits to sites 2, 3 and 5 identified facilitators and barriers to advancing TBC, echoed in the recorded notes from the weekly coach-mentor calls.

- Actionable data were a major barrier to pursuing improvement initiatives. Data reports generated by the electronic health record were either not readily available, not reliable or difficult to interpret. Many team members lacked data analytical skills prior to joining the collaborative.
- Leadership support for participation in the collaborative and for teams' ability to make decisions was cited as critical. The higher performing teams (sites 2 and 5 ) were given time to meet regularly and had access to data. Site 5 was 'given the autonomy to drive the change and choose their intervention [initiative]... ideas came from the team and staff and were not top-down...ownership by the team of changes also made it more successful. In contrast, the low-performing team at site 3 struggled to find time to meet throughout the collaborative and had little data. They noted 'if teams want to propose changes to workflow, they submit them to the Leadership and the Board for approval which caused delays and dampened enthusiasm.

Finally, coaches at all three sites endorsed the importance of the weekly coach-mentor calls: 'hearing what other participants in the collaborative were working on and learning from their best practices was such a valuable component of the Collaborative'.

\section{DISCUSSION}

The results suggest that primary care teams that committed to the work of the learning collaborative on TBC gained knowledge to assess and improve an area of practice and developed coaching and QI skills to advance TBC. All of the teams and coaches that completed before and after self-assessments-primary care team guide assessment and coach and team skills self-assessmentsreported improvements. While some were statistically significant, the small numbers make generalisability a challenge, a common problem for short-term learning collaboratives which typically consist of a dozen teams. ${ }^{14}$ Nine teams submitted a total of 11 playbooks, three reported improved efficiencies at the service level and one improved patient-level outcomes, thus attaining high levels of achievement on the improvement ramp. The data submitted by these four teams were not expected to be statistically significant; rather, the data demonstrated that teams learnt how to measure changes.

Eight months is insufficient time to achieve durable statistically significant patient outcomes when a learning collaborative is designed to help teams develop the skills to achieve those outcomes and access to reliable data is a barrier. It is enough time to demonstrate uptake of those skills needed to advance TBC. Even the decrease in some domains of the primary care team guide assessment suggests that as participating teams became better informed about TBC, their self-assessments became more valid and reflective of their values. ${ }^{33}$ It is also important to note that each team in our collaborative embarked on a different improvement initiative. By contrast, other learning collaboratives spend years with a focus on a single area of practice to achieve sustainable results, such as neonatal intensive care ${ }^{35}$ or cardiovascular disease. ${ }^{36}$

As with any learning collaborative, there were high and low-performing teams. Nembhard ${ }^{37}$ has identified determinants of teams' success in collaboratives that support 


\begin{tabular}{|c|c|c|c|c|c|c|}
\hline \multirow[b]{2}{*}{ Site } & \multicolumn{4}{|c|}{$\begin{array}{l}\text { Implementation outcomes: adoption/uptake } \\
\text { Actions to engage in the work of the collaborative }\end{array}$} & \multirow{2}{*}{$\begin{array}{l}\begin{array}{l}\text { Improvement } \\
\text { initiatives }\end{array} \\
\\
\text { Types of initiatives } \dagger\end{array}$} & \multirow{2}{*}{$\begin{array}{l}\begin{array}{l}\text { Service outcomes or } \\
\text { patient outcomes }\end{array} \\
\text { Reported changes in } \\
\text { service efficiency or in } \\
\text { patient health }\end{array}$} \\
\hline & $\begin{array}{l}\% \text { attendance } \\
\text { Learning sessions } \\
\text { (n7) (median71\%) }\end{array}$ & $\begin{array}{l}\% \text { attendance } \\
\text { Mentor-coach calls* } \\
\text { (median } 71.5 \% \text { ) }\end{array}$ & $\begin{array}{l}\text { Number of } \\
\text { assignments } \\
\text { submitted (of 7) } \\
\text { (median 7) }\end{array}$ & $\begin{array}{l}\text { Regularity of } \\
\text { weekly team } \\
\text { meetings }\end{array}$ & & \\
\hline 1 & $71 \%(5 / 7)$ & $93 \%(25 / 27)$ & 7 & Most of the time & $\begin{array}{l}\text { Cervical cancer } \\
\text { screening } \dagger\end{array}$ & \\
\hline 2 & $86 \%(6 / 7)$ & $83 \%(24 / 29)$ & 7 & Most of the time & $\begin{array}{l}\text { Diabetes care } \\
\text { (DidNotShow letters) } \dagger\end{array}$ & \\
\hline 3 & $100 \%(7 / 7)$ & $76 \%(22 / 29)$ & 6 & $\begin{array}{l}\text { Irregular } \\
\text { meetings }\end{array}$ & $\begin{array}{l}\text { Efficient office visit } \\
\text { workflow (cycle time) }\end{array}$ & \\
\hline 4 & $71 \%(5 / 7)$ & $83 \%(24 / 29)$ & 7 & Most of the time & $\begin{array}{l}\text { Cervical cancer } \\
\text { screening } \dagger\end{array}$ & $\begin{array}{l}\text { Increased cervical cancer } \\
\text { screening rates from } 32 \% \\
\text { to } 40 \%\end{array}$ \\
\hline 5 & $86 \%(6 / 7)$ & $85 \%(23 / 27)$ & 7 & $\begin{array}{l}\text { Almost all of the } \\
\text { time }\end{array}$ & $\begin{array}{l}\text { Efficient office visit } \\
\text { workflow } \dagger \\
\text { Early arrival time } \\
\text { communication } \dagger\end{array}$ & \\
\hline 6 & $86 \%(6 / 7)$ & $72 \%(21 / 29)$ & 7 & $\begin{array}{l}\text { Almost all of the } \\
\text { time }\end{array}$ & $\begin{array}{l}\text { Mammography } \\
\text { screening† }\end{array}$ & $\begin{array}{l}\text { Increased mammography } \\
\text { screening rates from } 67 \% \\
\text { to } 71 \%\end{array}$ \\
\hline 7 & $71 \%(5 / 7)$ & $31 \%(9 / 29)$ & 7 & Most of the time & Reducing no shows $†$ & $\begin{array}{l}\text { Improved rate of } \\
\text { rescheduling patients who } \\
\text { had not shown up for an } \\
\text { appointment, from } 37 \% \\
\text { to } 57 \%\end{array}$ \\
\hline 8 & $57 \%(4 / 7)$ & $21 \%(6 / 29)$ & 7 & $\begin{array}{l}\text { Stopped } \\
\text { meeting }\end{array}$ & $\begin{array}{l}\text { Access to appointment } \\
\text { process }\end{array}$ & \\
\hline 9 & $71 \%(5 / 7)$ & $44 \%(12 / 27)$ & 6 & Most of the time & $\begin{array}{l}\text { Patient experience } \\
\text { and clinical workflows } \\
\text { redesign (chart prep for } \\
\text { post emergency room } \\
\text { visits)† }\end{array}$ & \\
\hline 10 & $71 \%(5 / 7)$ & $63 \%(17 / 27)$ & 5 & $\begin{array}{l}\text { Irregular } \\
\text { meetings }\end{array}$ & $\begin{array}{l}\text { Improving control of } \\
\text { hypertension and low- } \\
\text { density lipoprotein (LDL) }\end{array}$ & \\
\hline 11 & $29 \%(2 / 7)$ & $14 \%(4 / 29)$ & 2 & $\begin{array}{l}\text { Stopped } \\
\text { meeting }\end{array}$ & & \\
\hline 12 & $86 \%(6 / 7)$ & $37 \%(10 / 27)$ & 6 & Most of the time & $\begin{array}{l}\text { Pre visit planning } \dagger \\
\text { Referral process } \dagger\end{array}$ & \\
\hline 13 & $100 \%(7 / 7)$ & $78 \%(21 / 27)$ & 7 & Most of the time & $\begin{array}{l}\text { Uncontrolled diabetes } \\
\text { interventiont }\end{array}$ & $\begin{array}{l}\text { Decrease in } \mathrm{HbA1c} \text { in } \\
\text { population of patients with } \\
\text { diabetes, from } 10.44 \text { to } \\
8.6 \text {, in } 6 \text { months }\end{array}$ \\
\hline
\end{tabular}

*One National Cooperative Agreement (NCA) coach held 29 calls, the other NCA coach held 27 calls. †Indicates a playbook was submitted for the improvement initiative.

our own findings: a combination of interorganisation learning activities (activities in which organisations have the opportunity to learn from each other), intraorganisation learning activities (when teams work with colleagues in their organisation) and organisational support. For our learning collaborative on $\mathrm{TBC}$, the interorganisation learning activities included the 2-day in-person boot camp, the seven interactive learning sessions and the weekly coach-mentor calls. For intraorganisation learning activities, we can cite consistency of weekly team meetings, use of the practice self-assessment tools and submission of team QI assignments related to improvement initiatives.
Teams needed organisational support to engage in these activities, and despite their leaderships' written commitment, some teams did not get it. Teams at sites 8 and 11 stopped participating due to competing organisational priorities. While site 3 struggled to engage in the intraorganisational activities, their coach remained active in the interorganisational activities, and submitted most of the QI assignments on her own. By contrast, sites 5 and 6 were actively engaged in all activities throughout the collaborative; they both produced playbooks and site 6 reported improved screening rates. Leadership from site 5 was so pleased with their teams' work in the ТВC 
Collaborative that they created a new role for one of their two coaches to spread QI and TBC throughout the organisation. By comparison, the coach from site 3, discouraged, left her job.

An important strength of the learning collaborative on TBC was using both external (NCA) and internal (FQHC) coaches. ${ }^{25}$ The coaching by the NCA coachmentors and the proactive execution of the collaborative by the NCA team provided highly valued support outside of the teams' own organisations. We did not provide technical assistance by request; we were proactive partners in the teams' efforts.

Future evaluation of learning collaboratives would benefit from more attention to coaching/facilitation and to execution, a factor in implementation science ${ }^{38}$ that has not been adequately studied in healthcare. The structure and content of collaboratives vary widely ${ }^{39}$ as does the complexity of the organisations that participate in them. Published protocols often focus on clinical outcomes, but not how the collaborative was executed, or how coaching was done, if at all. It is also important to understand how the intended change in practice was implemented by the participants in the unique context of their organisations' structure, resources, leadership engagement and skill set for implementing change. ${ }^{17} 19203840-45$

\section{CONCLUSION}

In this paper, we report on the extent to which 13 primary care teams from FQHCs in the USA availed themselves of the activities and resources offered by an 8-month learning collaborative for TBC. We examined selfreported changes in practice, and outcomes at the implementation, service and patient levels. The collaborative advanced the ability of engaged teams to assess their practice against central concepts of TBC, and to use QI skills to change that practice. A key characteristic of the 8-month collaborative was the role of the NCA team, and especially the mentor-coaches, whose weekly support for the FQHC improvement coaches was proactive.

Developing team capacity and capabilities for successful and sustainable $\mathrm{TBC}$ requires organisational investment in not just the short-term collaborative learning activities. It also requires long-term work, including protected time for teams to meet regularly, access to reliable data and coaching. Innovations in practice, such as TBC, require context conducive to change and attention to details in making the change ${ }^{46}$ such as reliability of data, steps in critical processes and clarification of roles. There is no substitute for time on task and the skills, teamwork and support to make good use of that time.

Twitter Kathleen Thies @Weitzmanlnst

Contributors KT and AS led the writing of the manuscript. KT developed the theory, verified and performed the analytical methods. KT and NK performed the computations. AS, AMH and KH contributed to the revisions of the manuscript. AMH, $\mathrm{KH}$ and DW contributed to the design and implementation of the intervention. All authors discussed the results and contributed to the final manuscript.
Funding Grant number U30CS29049 from the US Department of Health and Human Services Health Resources Services Administration to Community Health Center, Inc.

\section{Competing interests None declared.}

Patient and public involvement Patients and/or the public were not involved in the design, or conduct, or reporting, or dissemination plans of this research.

Patient consent for publication Not required.

Ethics approval This study was approved by the CHCl Institutional Review Board. Provenance and peer review Not commissioned; externally peer reviewed.

Data availability statement Data are available upon reasonable request. Upon request, raw data from surveys can be made available.

Open access This is an open access article distributed in accordance with the Creative Commons Attribution Non Commercial (CC BY-NC 4.0) license, which permits others to distribute, remix, adapt, build upon this work non-commercially, and license their derivative works on different terms, provided the original work is properly cited, appropriate credit is given, any changes made indicated, and the use is non-commercial. See: http://creativecommons.org/licenses/by-nc/4.0/.

ORCID iD

Kathleen Thies http://orcid.org/0000-0002-4954-4530

\section{REFERENCES}

1 Bodenheimer T, Sinsky C. From triple to quadruple aim: care of the patient requires care of the provider. Ann Fam Med 2014;12:573-6.

2 Coleman K, Reid R, Phillips KE, et al. Continuous and team-based healing relationships: improving patient care through teams. safety net medical home initiative. Seattle: Qualis Health The MacColl Center, 2014.

3 Safety Net Medical Home Initiative. Implementation guide series, 2019. Available: http://www.safetynetmedicalhome.org/resourcestools/implementation-guides [Accessed Dec 2019].

4 Bodenheimer T, Ghorob A, Willard-Grace R, et al. The 10 building blocks of high-performing primary care. Ann Fam Med 2014;12:166-71.

5 Berry LL, Beckham D. Team-Based care at Mayo clinic: a model for ACOs. J Healthc Manag 2014;59:9-13.

6 Health Resources Services Administration, Health Center Program. 2018 National health center data. Available: https://bphc.hrsa.gov/ uds/datacenter.aspx [Accessed 14 Apr 2020].

7 Reid R. Transforming Primary Care: Evaluating the Spread of Group Health's Medical Home, 2015. Available: https://www.ahrq.gov/sites/ default/files/wysiwyg/professionals/systems/primary-care/tpc/tpcprofile-reid.pdf [Accessed Mar 2016].

8 Reiss-Brennan B, Brunisholz KD, Dredge C, et al. Association of integrated team-based care with health care quality, utilization, and cost. JAMA 2016;316:826-34.

9 Health Resources Services Administration. HRSA accreditation and patient-centered medical home recognition initiative, 2019. Available: https://bphc.hrsa.gov/qualityimprovement/clinicalquality/ accreditation-pcmh/index.html [Accessed Dec 2019].

10 Sevin C, Moore G, Shepherd J, et al. Transforming care teams to provide the best possible patient-centered, collaborative care. $J$ Ambul Care Manage 2009;32:24-31.

11 Bodenheimer T. Lessons from the trenches--a high-functioning primary care clinic. N Engl J Med 2011;365:5-8.

12 Peikes DN, Reid RJ, Day TJ, et al. Staffing patterns of primary care practices in the comprehensive primary care initiative. Ann Fam Med 2014;12:142-9.

13 Yarnall KS, Østbye T, Krause KM, et al. Peer Reviewed: Family Physicians as Team Leaders:"Time" to Share the Care. Prev Chronic Dis 2009;6.

14 Institute for Healthcare Improvement. The breakthrough series: IHI's collaborative model for achieving breakthrough improvement, 2003.

15 Daily S, Tout K, Douglass A. Culture of continuous learning project: a literature review of the breakthrough series collaborative (BSC). Washington, DC: Department of Health and Human Services Administration for Children \& Families, 2018. https://www.acf.hhs. gov/opre

16 Ayers LR, Beyea SC, Godfrey MM, et al. Quality improvement learning Collaboratives. Qual Manag Health Care 2005;14:234-47.

17 De Silva D. Improvement Collaboratives in health care, evidence scan. London: Health Foundation, 2014. 
18 ØVretveit J, Bate P, Cleary P, et al. Quality Collaboratives: lessons from research. Qual Saf Health Care 2002;11:345-51.

19 Schouten LMT, Hulscher MEJL, van Everdingen JJE, et al. Evidence for the impact of quality improvement Collaboratives: systematic review. BMJ 2008;336:1491-4.

20 Wells S, Tamir O, Gray J, et al. Are quality improvement Collaboratives effective? A systematic review. BMJ Qual Saf 2018;27:226-40.

21 Dyess SM, Sherman R, Opalinski A, et al. Structured coaching programs to develop staff. J Contin Educ Nurs 2017;48:373-8.

22 Godfrey MM, Andersson-Gare B, Nelson EC, et al. Coaching interprofessional health care improvement teams: the coachee, the coach and the leader perspectives. J Nurs Manag 2014;22:452-64.

23 Grumbach K, Bainbridge E, Bodenheimer T. Facilitating improvement in primary care: the promise of practice coaching. issue brief (common fund). , 2012: 15, 14.

24 Nelson EC, Batalden PB, Godfrey MM. Quality by design: a clinical microsystems approach. Hoboken, NJ: John Wiley \& Sons, 2011.

25 The Dartmouth Institute. Microsystem Academy: team coaching Academy, 2020.

26 McChesney C, Covey S, Huling J. The 4 disciplines of execution: achieving your wildly important goals. New York: Simon and Schuster, 2012.

27 Sull DN. Closing the gap between strategy and execution. MIT Sloan Manage Rev 2007;48:30.

28 Sull D, Homkes R, Sull C. Why strategy execution unravels-and what to do about it. Harv Bus Rev 2015;93:57-66.

29 Improving Primary Care. Primary care team guide assessment, 2020. http://www.improvingprimarycare.org

30 The Dartmouth Institute. Microsystem Academy: coach skills selfassessment.

31 The Dartmouth Institute. Microsystem Academy: team skills selfassessment.

32 Proctor E, Silmere H, Raghavan R, et al. Outcomes for implementation research: conceptual distinctions, measurement challenges, and research agenda. Adm Policy Ment Health 2011;38:65-76.
33 Fisher RJ, Katz JE. Social-desirability bias and the validity of selfreported values. Psychol. Mark. 2000;17:105-20.

34 R Core Team. R: a language and environment for statistical computing, 2019.

35 Vermont Oxford Network. Available: https://public.vtoxford.org [Accessed Mar 2020].

36 The Northern new England cardiovascular disease Study Group (NNECDSG). Available: http://nnecdsg.org/ [Accessed Mar 2020].

37 Nembhard IMAll teach, all learn, all improve?: the role of interorganizational learning in quality improvement Collaboratives. Health Care Manage Rev 2012;37.

38 Damschroder LJ, Aron DC, Keith RE, et al. Fostering implementation of health services research findings into practice: a consolidated framework for advancing implementation science. Implement Sci 2009;4:50.

39 Nembhard IM. Learning and improving in quality improvement Collaboratives: which collaborative features do participants value most? Health Serv Res 2009;44:359-78.

40 Dixon-Woods M. The problem of context in quality improvement. Perspectives on context. London: Health Foundation, 2014: 87-101.

41 Harvey G, Kitson A. PARIHS revisited: from heuristic to integrated framework for the successful implementation of knowledge into practice. Implement Sci 2015;11:33.

42 Kitson AL, Rycroft-Malone J, Harvey G, et al. Evaluating the successful implementation of evidence into practice using the PARiHS framework: theoretical and practical challenges. Implement Sci 2008;3:1.

43 Nadeem E, Olin SS, Hill LC, et al. Understanding the components of quality improvement Collaboratives: a systematic literature review. Milbank Q 2013;91:354-94.

44 Pawson R, Tilley N, Evaluation R. Realsit evaluation. London: Sage, 1997.

45 Øvretveit J. Evaluating improvement and implementation for health London: McGraw-Hill Education (UK), 2014.

46 Naveh E, Erez M. Innovation and attention to detail in the quality improvement paradigm. Manage Sci 2004;50:1576-86. 